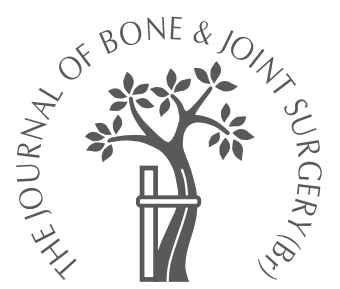
W. Pötzl,
P. Kümpers,
T. Szuwart,
C. Götze,
B. Marquardt,
J. Steinbeck

From the University Hospital, Münster, Germany

\title{
Immobilisation after radiofrequency-induced shrinkage of tendon
}

\author{
A HISTOLOGICAL STUDY IN RABBITS
}

W. Pötzl, MD, Orthopaedic Surgeon

P. Kümpers, Student

G. Götze, MD, Orthopaedic

Surgeon

B. Marquardt, MD,

Orthopaedic Surgeon

J. Steinbeck, MD,

Orthopaedic Surgeon

Department of Orthopaedics,

University Hospital Münster,

Albert-Schweitzer Strasse

33, 48149 Münster, Germany.

T. Szuwart, PhD,

Orthopaedic Surgeon

Institut for Anatomy,

Westphalian Wilhelms-

University Münster,

Vesaliusweg 2-4, 48149

Münster, Germany.

Correspondence should be sent to Dr W. Pötzl.

C2004 British Editorial Society of Bone and

Joint Surgery

doi:10.1302/0301-620X.86B5

$14778 \$ 2.00$

$J$ Bone Joint Surg [Br]

2004;86-B:752-8.

Received 10 July 2003;

Accepted after revision

9 October 2003

Despite widespread use of radiofrequency (RF) shrinkage, there have been no animal studies on the effects of post-operative immobilisation on the histological properties of the shrunken tissue. We have therefore examined the role of post-operative immobilisation after RF shrinkage with special emphasis on the histological properties of collagenous tissue.

One patellar tendon of 66 New Zealand White rabbits was shrunk. Six rabbits were killed immediately after the operation. Twenty rabbits were not immobilised, 20 were immobilised for three weeks and $\mathbf{2 0}$ for six weeks. Fibroblasts, collagen and vascular quality and density were evaluated on sections, stained by haematoxylin and eosin.

Nine weeks after operation the histological properties were inferior to those of the contralateral control tendons. Shrunk tendons did not return to normal at any time after operation irrespective of whether the animals had been immobilised or not. All the parameters improved significantly between zero and three weeks after operation. Immobilised tendons tended to have a better and faster recovery.

Careful rehabilitation is imperative after RF shrinkage. Immobilisation aids recovery of the histological properties. Our findings in this animal model support a period of immobilisation of more than three weeks.

The use of thermal energy to shorten redundant collagenous tissue has been examined as a method for increasing the stability of the joint. ${ }^{1-9}$ The application of radiofrequency (RF) energy for the treatment of the redundant joint capsule in patients with glenohumeral instability has become widespread in orthopaedic surgery, although only a limited number of in vivo animal studies are available $2,4,6,9-14$ and the long-term clinical results of this procedure have not yet been reported. ${ }^{15-18}$

Several studies have examined the influence of thermal treatment on the histological prop-

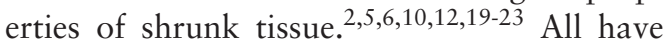
described the initial thermal damage to the shrunk collagenous tissue which is characterised by hyalinisation of collagen and fibroblastic cell necrosis. Some of these studies analysed the post-operative tissue between seven days and six months after operation and found an active cellular response characterised by increased cellularity and vascularity. ${ }^{6,10,12,21,22}$ In none of these studies had the animals been immobilised during the post-operative period.

We are not aware of any animal study on the role of post-operative immobilisation after RFinduced shrinkage of collagenous tissue, although it seems to be the general clinical practice to immobilise a joint for several weeks after a capsular shrinkage procedure.

Our aim therefore was to examine the effect of post-operative immobilisation after RFinduced shrinkage, with special emphasis on the histological damage.

\section{Materials and Methods}

We used 66 skeletally mature New Zealand White rabbits weighing from 3.5 to $5.5 \mathrm{~kg}$. The study was approved by the local Institutional Animal Use and Care Committee. All the animals had been purchased from a single supplier and allowed to acclimatise for at least one week before surgery.

The rabbits were anaesthetised with an intramuscular injection of ketamine hydrochloride (15 mg/kg) and xylazine $(2 \mathrm{mg} / \mathrm{kg}$ ). To maintain anaesthesia the injection was repeated every 20 minutes during the operation.

The right knee of all the rabbits was shaved and prepared for aseptic surgery. The patellar tendon was approached through a medial parapatellar incision and loose areolar connective tissue was removed from its surface. The tendon was marked with a surgical marker 
Table I. The subjective scoring system for the quality of fibroblasts and collagen according to Hecht et $\mathrm{al}^{10}$

\begin{tabular}{llcl}
\hline Fibroblasts & $\begin{array}{l}\text { Dead cells, } \\
\text { nuclear karyorhexis }\end{array}$ & $\begin{array}{l}\text { Proliferative, } \\
\text { active cells }\end{array}$ & $\begin{array}{l}\text { Normal, spindle- } \\
\text { shaped cells }\end{array}$ \\
\hline $\begin{array}{l}\text { Collagen (light and } \\
\text { polarised light microscopy) }\end{array}$ & Hyalinisation & Unorganised bundles & $\begin{array}{l}\text { Laminar organised, } \\
\text { normal }\end{array}$ \\
\hline Score & & Percentage & \\
\hline 9 & 100 & 0 & 0 \\
8 & 75 & 25 & 0 \\
7 & 50 & 50 & 0 \\
6 & 25 & 75 & 0 \\
5 & 0 & 100 & 0 \\
4 & 0 & 75 & 25 \\
3 & 0 & 50 & 75 \\
2 & 0 & 25 & 100
\end{tabular}

Table II. Subjective scoring system of the vascular quality and density according to Hecht et al $^{10}$

\begin{tabular}{llll}
\hline Score & $\mathbf{1}$ & $\mathbf{2}$ & $\mathbf{3}$ \\
\hline Vascular quality & $\begin{array}{l}\text { Normal appearance of Plump endothelial cells, } \\
\text { vessels }\end{array}$ & $\begin{array}{l}\text { Occluded vessels, pyknotic } \\
\text { endothelial cells }\end{array}$ \\
Vascular density & Normal amount & $\begin{array}{l}\text { Increased amount } \\
\text { Increased amount of dead cells }\end{array}$ & \begin{tabular}{l} 
Incrouting \\
\hline
\end{tabular}
\end{tabular}

every $5 \mathrm{~mm}$ between the patellar and the proximal tibial wire to allow consistent application of energy.

The RF energy was delivered to the tendon using an RF generator (Vapr II; Mitek Division Ethicon, Norderstedt, Germany) at a temperature setting of $70^{\circ} \mathrm{C}$ and a power setting of $40 \mathrm{~W}$, coupled with a bipolar, temperature-controlled probe (Vapr TC; Mitek Division Ethicon). In order to allow the probe to be used under saline a plastic cup of $10 \mathrm{~cm}$ in diameter equipped with a rubber base was placed over the knee. A slit in the rubber base of the cup allowed the patella, patellar tendon and proximal tibia to protrude into the cup. This was then filled with saline and a consistent medial-to-lateral grid pattern was used moving the probe from proximal to distal at a velocity of approximately 1 to $2 \mathrm{~mm} / \mathrm{sec}$ with the parallel passes spaced approximately $5 \mathrm{~mm}$ apart. The incision was closed with simple interrupted 3-0 vicryl sutures (Vicryl; Ethicon).

After operation, the rabbits were divided into different groups according to the immobilisation plan. Six were killed immediately after the operation. Twenty were allowed normal cage activity without any immobilisation. Ten of these were killed after three weeks, and ten after nine weeks. Twenty were immobilised in a cast for three weeks; of which ten were killed directly after removal of the cast at three weeks and ten were allowed normal cage activity for another three weeks without a cast and were killed six weeks after surgery. Finally, 20 were immobilised in a cast for six weeks; ten of these were killed directly after removal of the cast at six weeks, and ten were allowed normal cage activity for another three weeks without a cast and were killed nine weeks after surgery.

The patella, patellar tendon and proximal tibia were disarticulated as a unit from the remainder of the limb in both hindlimbs in all rabbits. The left leg served as a control. The skin and subcutaneous tissue were carefully removed and the tendons were wrapped in saline swabs and frozen at $-80^{\circ} \mathrm{C}$. After thawing of the patella-patellar-tendon-tibial complexes specimens $0.6 \mathrm{~mm} \times 0.3 \mathrm{~mm} \times 0.3 \mathrm{~mm}$ in size were cut from each patellar tendon close to the tibial insertion of the tendon. The specimens were fixed in neutral buffered $7 \%$ formalin. They were embedded in paraffin and sections $5 \mu \mathrm{m}$ thick were cut in the sagittal plane. These were stained with haematoxylin and eosin and examined by light microscopy and polarised light microscopy. Two specimens from the left limbs of each group were selected at random for use as controls.

In order to evaluate the effect of RF energy on collagenous tissue, we used a subjective scoring system according to Hecht et al. ${ }^{10}$ All the tissue sections were evaluated and graded in a blinded manner. The scoring system for the quality of fibroblasts and collagen is shown in Table I. The grading of quality and the density of vessels was also performed according to Hecht et $\mathrm{al}^{10}$ (Table II).

Statistical analysis. The scores were reported as the mean value with SD. A Mann-Whitney U test was used to evaluate differences between different groups. The level of significance was set at $5 \%$.

\section{Results}

Fibroblasts. The fibroblasts in the control sections had a typical spindle-shaped appearance with no alterations of cell nuclei and cell orientation. The subjective mean score for the fibroblasts in the control tendons was 1.08 (SD $0.19)$.

Immediately after operation the fibroblasts showed marked changes with nuclear karyorrhexis (damage of the cell nucleus) and pyknosis of the nuclei. The mean score 


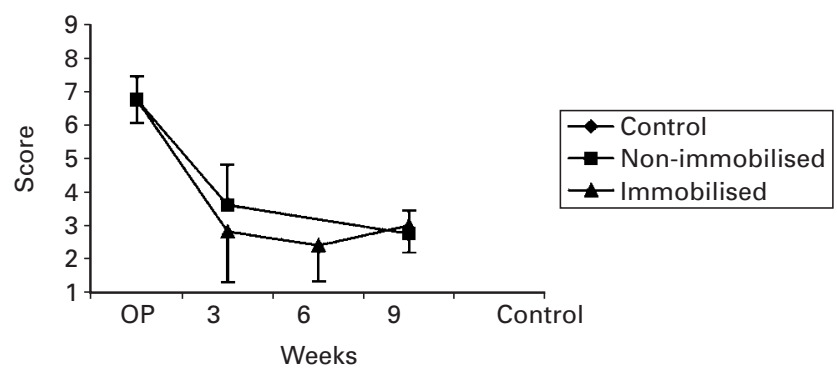

Fig. 1

Changes in mean scores for fibroblasts over the study period for the control, non-immobilised and immobilised groups.

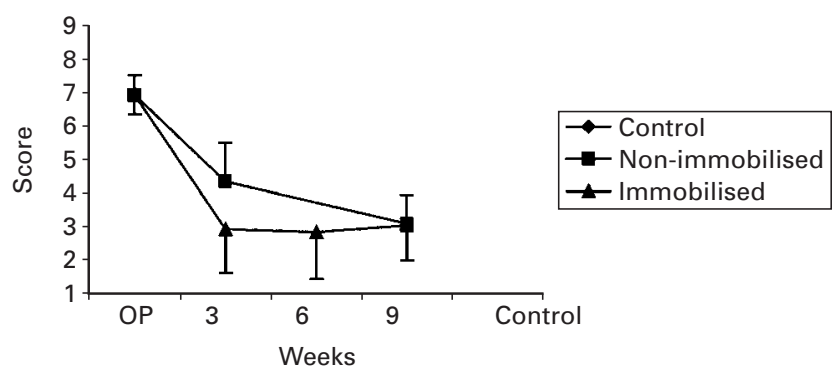

Fig. 2

Changes in mean scores for collagen under light microscopy over the study period for the control, non-immobilised and immobilised groups. was 6.75 (SD 0.69). Three weeks after operation the sections of the non-immobilised and immobilised limbs still showed changes in the morphology of the fibroblasts with polymorphic nuclei. The mean score for immobilised tendons was 2.81 (SD 1.51) and for non-immobilised tendons 3.55 (SD 1.21). This difference was not significant $(\mathrm{p}=$ $0.37)$.

Six weeks after operation the appearance of the fibroblasts was more similar to that of the control sections and the fibroblasts were more spindle-shaped. The mean score for immobilised tendons was 2.4 (SD 1.07). That for tendons which had been immobilised during the first three weeks and had a subsequent period of three weeks without immobilisation was 2.85 (SD 0.7). The difference was not significant $(\mathrm{p}=0.22)$.

Nine weeks after treatment the fibroblasts were similar to the spindle-shaped cells of the control sections. Despite the hypercellularity the cell orientation was almost normal. The mean score for non-immobilised tendons was 2.75 (SD $0.68)$. That for tendons which had been immobilised during the first six weeks was 3.00 (SD 0.82). The difference was not significant $(\mathrm{p}=0.43)$.

The change in the scores over the first three weeks showed a significant recovery of the fibroblasts in both the immobilised and the non-immobilised groups ( $\mathrm{p}=0.002)$. The further improvement in the scores was not statistically significant. At no time did the treated fibroblasts reach the score of the control sections irrespective of whether they had been immobilised or not. Nine weeks after operation the score of both groups had still increased compared with control tendons ( $\mathrm{p}<0.001)$ (Fig. 1).

Light-microscopic findings. The control sections had a normal appearance of wavy fibrous collagen bundles with a mean score of 1.08 (SD 0.19).

Immediately after the operation there was a loss of the normal fine fibrillar collagen structure and hyalinisation led to a mean score of 6.91 (SD 0.58).

Three weeks after operation the hyalinisation of the collagen structure had disappeared almost completely. Fine, but mainly unorganised, fibrillar bundles of collagen were visible. Sections of immobilised tendons showed some areas of organised collagen and had a mean score of 2.93 (SD 1.29). Non-immobilised tendons had completely unorganised collagen bundles and a mean score of 4.35 (SD 1.13). There was an apparent difference between immobilised and non-immobilised tendons but it was not significant $(\mathrm{p}=$ 0.054).

Six weeks after the operation, tissue from immobilised tendons had almost the same appearance as at three weeks. The mean score was 2.85 (SD 1.4). The sections of the tendons which had been immobilised during the first three weeks revealed some areas of organised collagen bundles and had a mean score of 3.00 (SD 0.67). The difference between the groups was not significant $(\mathrm{p}=0.731)$.

Nine weeks after operation both groups had areas of wavy organised collagen bundles next to some minor unorganised areas. The collagen bundles were more distinct and the tissue had a more homogenous appearance. The mean score for non-immobilised tendons was 3.10 (SD $0.84)$, and that for tendons which had been immobilised during the first six weeks was 3.05 (SD 1.03). The difference was not significant ( $\mathrm{p}=0.877)$.

The change in the scores for collagen quality throughout the study period revealed a significant improvement in the collagen in the first three weeks for both the immobilised and the non-immobilised tendons $(\mathrm{p}=0.002)$. The further recovery of the tissue was not statistically significant. The treated collagen did not recover sufficiently to reach the score of the control sections irrespective of whether it had been immobilised or not. Nine weeks after operation the mean score of both groups was still statistically worse compared with that of the control tissue ( $\mathrm{p}<0.001$; Figs. 2 and 3; Table III).

Polarised microscopic findings. The control sections had a normal, wavy birefringence. Since all sections had this appearance, the mean score for the control sections was 1.00 (SD 0.00). Immediately after treatment the normal collagen architecture had vanished. The bundles had a fused appearance and the intensity of birefringence was clearly reduced. The mean score was 6.0 (SD 1.1). 

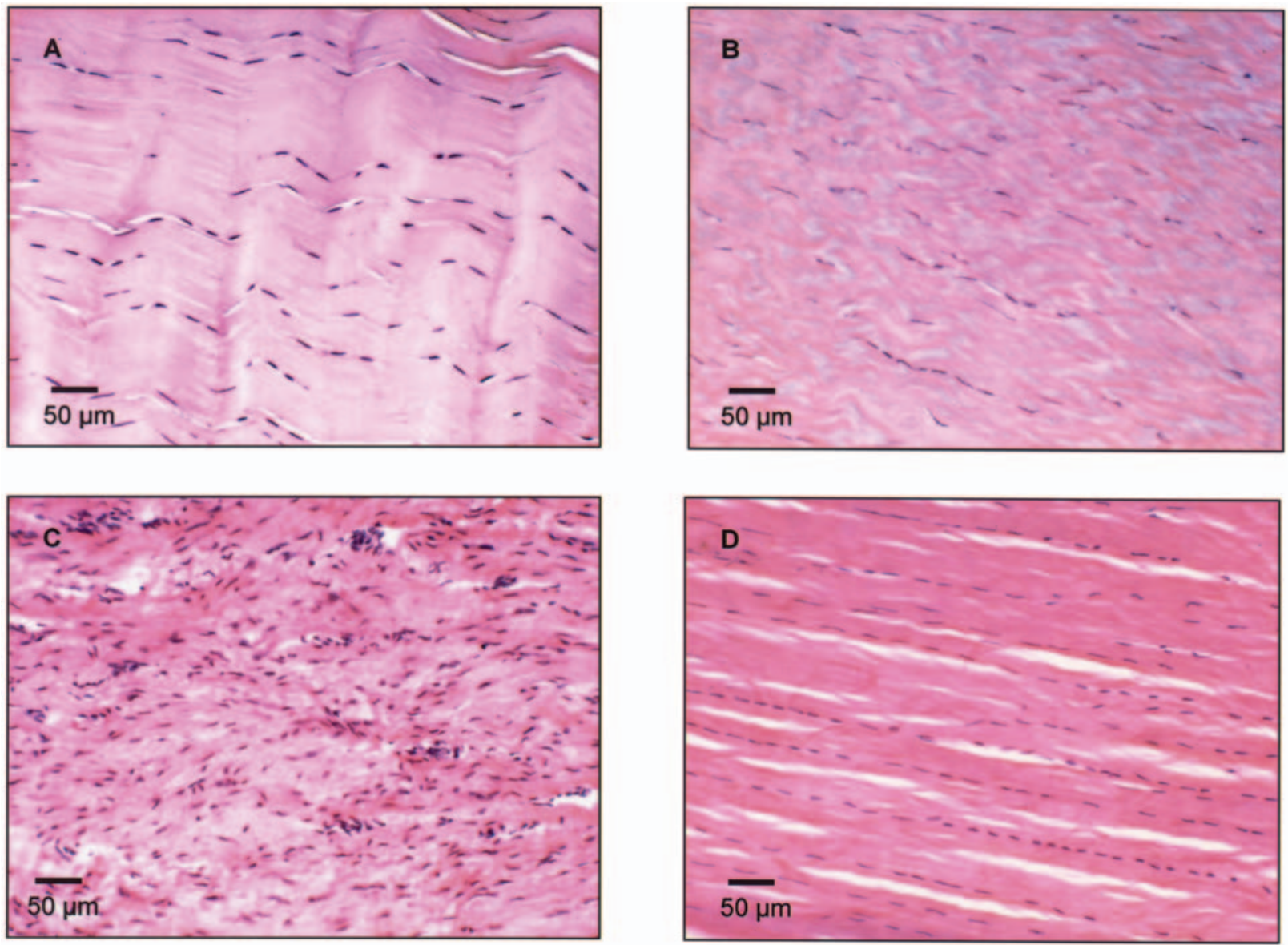

Fig. 3

Haematoxylin and eosin stains. a) Control tissue containing spindle shaped fibroblasts and laminar oriented collagen fibres. b) Immediately after treatment demonstrating marked structural changes. c) Three weeks without immobilisation: the collagen bundles are still completely unorganised. d) Three weeks with immobilisation: fine fibrillar collagen bundles are visible again.

Table III. Mean (SD) scores for fibroblasts and collagen under light and polarised light microscopy

\begin{tabular}{|c|c|c|c|}
\hline \multirow[b]{2}{*}{ Time (wks) } & \multirow[b]{2}{*}{ Fibroblasts } & \multicolumn{2}{|l|}{ Collagen } \\
\hline & & Light microscopy & Polarised microscopy \\
\hline 0 & $6.75(0.69)$ & $6.91(0.58)$ & $6.00(1.1)$ \\
\hline \multicolumn{4}{|c|}{ 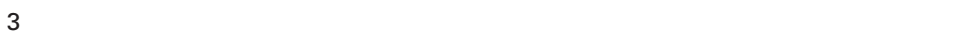 } \\
\hline Immobilised & $2.81(1.51)$ & $2.93(1.29)$ & $3.13(1.89)$ \\
\hline Non-immobilised & $3.55(1.21)$ & $4.35(1.13)$ & $4.69(1.35)$ \\
\hline \multicolumn{4}{|l|}{6} \\
\hline Immobilised & $2.40(1.07)$ & 2.85 (1.39) & $3.40(1.58)$ \\
\hline Part immobilised & $2.85(0.7)$ & $3.00(0.66)$ & $4.50(0.71)$ \\
\hline \multicolumn{4}{|l|}{9} \\
\hline Non-immobilised & $2.75(0.68)$ & $3.10(0.84)$ & $3.40(1.27)$ \\
\hline Part immobilised & $3.00(0.82)$ & $3.05(1.03)$ & $3.60(1.26)$ \\
\hline Control & $1.08(0.19)$ & $1.08(0.19)$ & $1.00(0.00)$ \\
\hline
\end{tabular}

Three weeks after operation the sections of immobilised and non-immobilised tendons had almost complete loss of birefringence with unorganised collagen bundles. The mean score for the immobilised tendons was 3.13 (SD 1.89), and that for non-immobilised tendons 4.69 (SD 1.35). The dif- ference between these groups was not significant $(p=$ $0.117)$.

At six weeks the tissue of the immobilised limbs showed the beginning of reorganisation of collagen bundles and the intensity of birefringence had improved. The mean score 

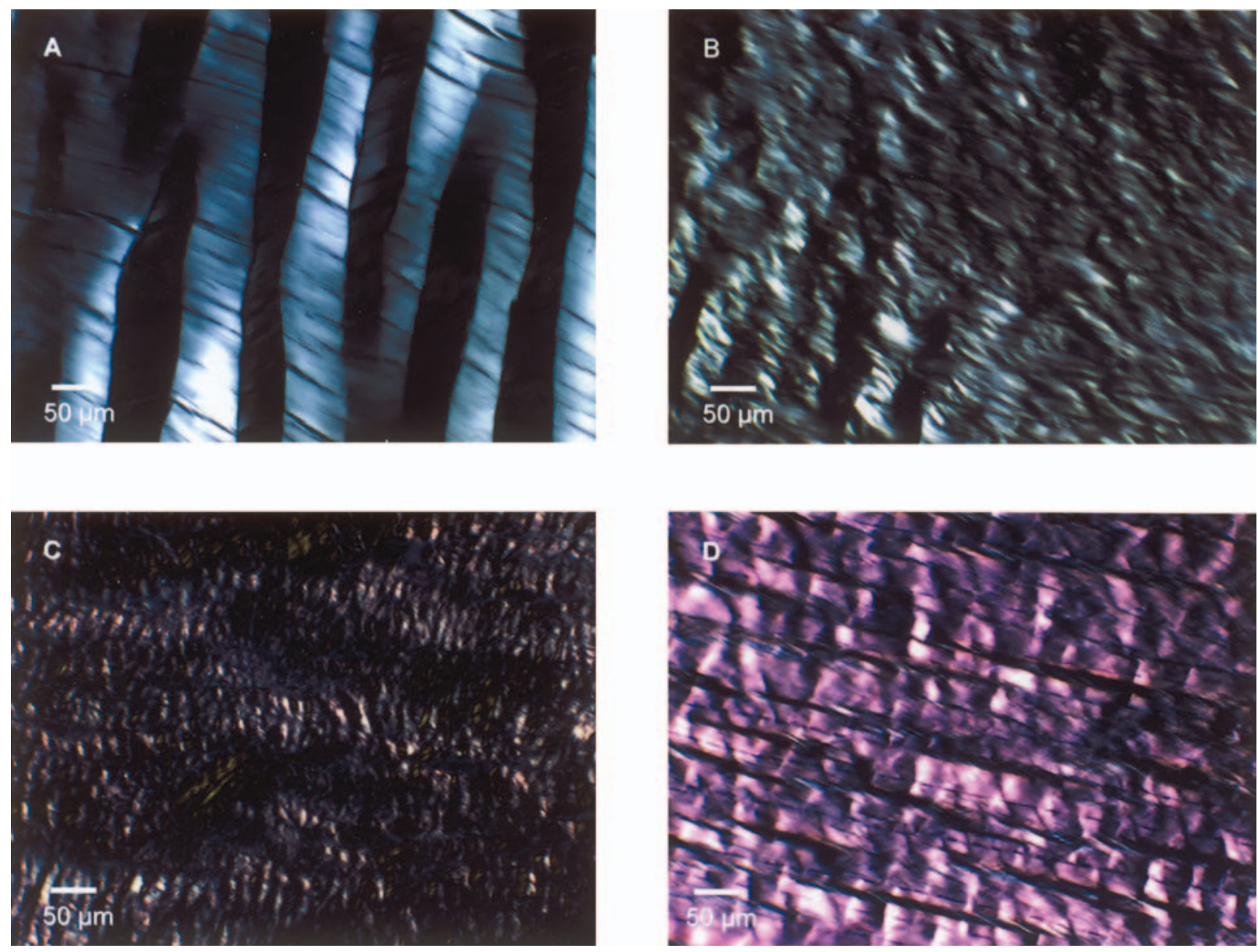

Fig. 4

Collagen bundles under polarised light microscopy a) control section containing normal wavy birefringence; b) immediately after treatment Fused collagen bundles with reduced intensity of birefringence; c) three weeks without immobilisation. Collagen bundles still fused and complete loss of birefringence. d) Three weeks with immobilisation. Normal collagen orientation and birefringence is recovering.

was 3.40 (SD 1.58). The tendons which had been immobilised for the first three weeks only had the same appearance as at three weeks. Their mean score was 4.50 (SD 0.71). The difference between completely immobilised and partially immobilised limbs was not statistically significant at six weeks $(\mathrm{p}=0.12)$.

By nine weeks both groups showed an improvement in collagen organisation. The mean score for tendons which had been immobilised during the first six weeks was 3.60 (SD 1.26). The mean score for non-immobilised limbs was 3.40 (SD 1.27). The difference was not significant $(\mathrm{p}=$ $0.69)$.

The time-related change in the scores for collagen quality showed a significant improvement of the organisation of collagen in the first three weeks. The difference for immobilised tendons was statistically significant ( $p=0.005)$, as was that for non-immobilised tendons $(p=0.049)$. The further recovery of the tissue was not statistically significant. At no time did the score of the treated samples reach that of the control sections irrespective of whether they had been immobilised or not. The mean score of both groups was still statistically worse at nine weeks compared with that of the control tissue $(\mathrm{p}<0.001)$ (Fig. 4; Table III).

Vascular quality and vascular density. In the control sections the endothelial cells of the vessels showed a normal spindle-shaped appearance of their nuclei and a low vascular density. The mean score for vascular quality and density was 1.00 (SD 0.00).

Immediately after the operation the tissue showed a marked alteration of the vascular quality with thrombosed vessels and endothelial cells necrosis. The mean score for vascular quality was 2.83 (SD 0.41 ). The density of the vessels was unchanged compared with the control sections but the vessels were seriously damaged and thus the mean score for vascular density was 2.83 (SD 0.41).

Three weeks after operation the sections showed almost complete regeneration of the endothelial cells. The tissue of the non-immobilised limbs had enlarged endothelial cells and a mean score for vascular quality of 1.95 (SD 0.28 ). The vessels of the immobilised tendons had smaller endothelial 


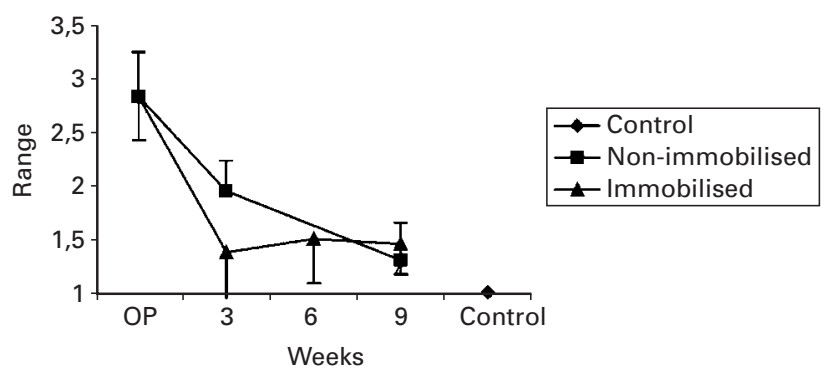

Fig. 5

Change in mean scores for vascular quality for the control, non-immobilised and immobilised groups.

cells and a mean score of 1.38 (SD 0.44). The difference in vascular quality between the groups was statistically significant at three weeks $(p=0.009)$. Both groups showed a marked increase in vascular density with hypervascularity. The mean score for vascular density of the non-immobilised tendons was 1.95 (SD 0.37); and that for the immobilised tendons was 1.63 (SD 0.44). This difference was not significant $(\mathrm{p}=0.07)$.

At six weeks the vascular quality of both groups was approximately the same as that in the group immobilised for three weeks. The mean score of the immobilised tissue was 1.5 (SD 0.41) and that for tendons which had been immobilised during the first three weeks 1.45 (SD 0.37). The difference was not significant $(\mathrm{p}=0.77)$. Both groups still had increased vascular density compared with the control sections. The mean score for vascular density in the immobilised limbs was 1.75 (SD 0.42) and that for tendons which had been immobilised during the first three weeks was 1.6 (SD 0.31). This difference was not significant $(\mathrm{p}=0.22)$.

By nine weeks the vascular quality had improved further. The score of the tissue which had been immobilised during the first six weeks was 1.45 (SD 0.28) and that for the nonimmobilised limbs was 1.30 (SD 0.34). This difference was not significant $(p=0.25)$. The score for vascular density was the same in both groups at nine weeks: 1.75 (immobilised, SD 0.42; non-immobilised, SD 0.35).

The changes in the score for vascular quality during the study showed a significant improvement in the first three weeks $(\mathrm{p}=0.002$ for non-immobilised limbs and $\mathrm{p}=0.003$ for immobilised limbs). At three weeks the vessels of the immobilised tissue had a significantly better quality than those of non-immobilised limbs $(\mathrm{p}=0.009)$. The further recovery of the vessels was not statistically significant for immobilised tendons. The vascular quality for non-immobilised tissue improved between three weeks and nine weeks $(\mathrm{p}<0.001)$.

The vascular density showed a similar improvement in the first three weeks ( $p=0.002$ for non-immobilised limbs and $p=0.003$ for immobilised limbs). The further improvement of the score for vascular density was not significant. At no time did the scores for the vascular quality or the den-
Table IV. Mean (SD) scores for vascular quality and density

\begin{tabular}{|c|c|c|}
\hline Time (wks) & Vascular quality & Vascular density \\
\hline 0 & $2.83(0.41)$ & $2.83(0.41)$ \\
\hline \multicolumn{3}{|l|}{3} \\
\hline Immobilised & $1.38(0.44)$ & $1.63(0.44)$ \\
\hline Non-immobilised & $1.95(0.28)$ & $1.95(0.37)$ \\
\hline \multicolumn{3}{|l|}{6} \\
\hline Immobilised & $1.50(0.41)$ & $1.75(0.42)$ \\
\hline Part immobilised & $1.45(0.37)$ & $1.600 .31)$ \\
\hline \multicolumn{3}{|l|}{9} \\
\hline Non-immobilised & $1.30(0.34)$ & $1.75(0.35)$ \\
\hline Part immobilised & $1.45(0.28)$ & $1.75(0.42)$ \\
\hline Control & $1.00(0.00)$ & $1.00(0.00)$ \\
\hline
\end{tabular}

sity of the shrunk tissue reach those of the control sections irrespective of whether the limbs had been immobilised or not. At nine weeks the mean score for both groups was worse compared with that for the control tissue $(p<0.001)$ (Fig. 5, Table IV).

\section{Discussion}

Thermal shrinkage of collagenous tissue has generated wide interest recently. In 1997 Pullin et al ${ }^{12}$ found in a canine model significant inflammation, necrosis and hypercellularity six weeks after laser-assisted shrinkage. Also Schaefer et $\mathrm{al}^{6}$ described in a rabbit model a generalised fibroblastic response which was characterised by a marked increase in cellularity and vascularity after eight weeks. In 1998 Hecht et al $^{22}$ found cell infiltration, collagen fusion and pyknosis of fibroblasts seven days after treatment in a sheep model. They showed that the area and depth of the thermal damage were influenced by the power setting of the $\mathrm{RF}$ generator. In another study Hecht et $\mathrm{al}^{10}$ examined changes in a sheep model after monopolar RF for two, six and 12 weeks. They also described early hyalinisation of collagen and cell necrosis followed by active tissue repair. After 12 weeks they found laminar collagenous tissue and a normal synovial membrane. ${ }^{10}$ Hayashi et al ${ }^{21}$ described the biological response to laser treatment in a sheep model with a post-operative follow-up of three, seven, 14, 30, 60, 90 and 180 days. They also found collagen hyalinisation and cell necrosis and found the tissue to be histologically normal after 60 days.

Our results are comparable to the findings of Schaefer et $\mathrm{al}^{6}$ and Pullin et $\mathrm{al}^{12}$ and are in contrast with those of Hayashi et $\mathrm{al}^{21}$ and Hecht et $\mathrm{al}^{22}$ who found a histologically normal appearance at six weeks and full recovery by 60 days.

Since this is the first in vivo animal study of the influence of post-operative immobilisation our results in the immobilised animals are not comparable with those of previous studies. It is not clear why the tissue did not recover completely despite immobilisation but one possible explanation is that the duration of immobilisation was too short. Recently published clinical studies have described the 
results of laser- and RF-induced capsular shrinkage in patients with impingement, multidirectional instability and capsular laxity. ${ }^{15-18}$ The patients were immobilised for two to three weeks and had a high rate of satisfactory results after a mean follow-up of two years. These promising clinical mid-term results are in contrast to our histological findings. It may be that we are unaware of the factors responsible for the clinical success of thermal treatment. Induction of fibrosis, thickening of the joint capsule or thermal denervation have been suggested as mechanisms. ${ }^{21}$

In a study on the role of immobilisation on post-operative tissue length Pötzl et $\mathrm{al}^{11}$ found that significant lengthening could not be prevented even with immobilisation. These observations correlate with our histological results which indicate that a period of six weeks of post-operative immobilisation is too short for complete recovery of the tissue.

The results of our study must be interpreted with caution. The patellar tendon of the rabbit is not the ideal model of the human shoulder. The difference between tendons and capsular ligaments should be taken into account. The structure and the collagen content of tendons and ligaments are not the same. Another important difference is that tendons are attached to muscles and even during immobilisation the muscles may pull on the tendons. It is difficult to compare the immobilisation of a rabbit's knee in a cast with the immobilisation of a human shoulder in a sling, but the differences between the non-immobilised and immobilised animals showed that immobilisation had a significant effect. The patellar tendon tissue in our model was normal, but pathological features of the joint capsule in glenohumeral instability have not been well defined. ${ }^{24}$ We were also unable to control the energy applied in the in vivo study as precisely as in in vitro studies. ${ }^{21}$

In conclusion our results demonstrate the considerable importance of careful post-operative rehabilitation after RF-induced shrinkage of collagenous tissue. In order to prevent serious damage shrunk tissue should be protected from normal physiological loads. The histological properties of shrunk tissue are markedly altered. This decrease in the tissue quality because of the thermal treatment is demonstrated by the post-operative lengthening of the treated tissue and the inferior biomechanical properties. ${ }^{6,9-11}$ Although there was a considerable improvement, in this animal model the treated tendons did not recover a normal histological appearance even under immobilising conditions.

The authors thank Mirko Brandes for his assistance with the project. This work was supported by a grant from the German Research Society (DFG) and from MITEK Division Ethicon, Norderstedt, Germany.

No other benefits in any form have been received or will be received from a commercial party related directly or indirectly to the subject of this article.

\section{References}

1. Hayashi K, Thabit G 3rd, Bogdanske JJ, Mascio LN, Merkel MD. The effect of nonablative laser energy on the ultrastructure of joint capsular collagen. Arthroscopy 1996;12:474-81.

2. Hayashi $\mathbf{K}$, Thabit $\mathbf{G}$ 3rd, Massa $\mathbf{K L}$, et al. The effect of thermal heating on the length and histologic properties of the glenohumeral joint capsule. Am J Sports Med 1997;25:107-12.

3. Hayashi K, Peters DM, Thabit G 3rd, et al. The mechanism of joint capsule thermal modification in an in-vitro sheep model. Clin Orthop 2000;370:236-49.

4. Lu Y, Hayashi K, Edwards RB 3rd, et al. The effect of monopolar radiofrequency treatment pattern on joint capsule healing: in vitro and in vivo studies using an ovine model. Am J Sports Med 2000;28:711-19.

5. Naseef GS 3rd, Foster TE, Trauner K, et al. The thermal properties of bovine joint capsule: the basic science of laser- and radiofrequency-induced capsular shrinkage. Am J Sports Med 1997;25:670-4.

6. Schaefer SL, Ciarelli MJ, Arnoczky SP, Ross HE. Tissue shrinkage with the holmium: yttrium aluminium garnet laser: a postoperative assessment of tissue length, stiffness, and structure. Am J Sports Med 1997;25:841-8.

7. Selecky MT, Vangsness CT Jr, Liao WL, Saadot V, Hedman TP. The effects of laser-induced collagen shortening on the biomechanical properties of the inferior glenohumeral ligament complex. Am J Sports Med 1999;27:168-72.

8. Tibone JE, McMahon PJ, Shrader TA, Sandusky MD, Lee TO. Glenohumeral joint translation after arthroscopic, nonablative, thermal capsuloplasty with a laser. Am J Sports Med 1998;26:495-8.

9. Wallace AL, Hollinshead RM, Frank CB. Electrothermal shrinkage reduces laxity but alters creep behaviour in a lapine ligament model. J Shoulder Elbow Surg 2001; 10:1-6.

10. Hecht $\mathbf{P}$, Hayashi $K$, Lu $\mathbf{Y}$, et al. Monopolar radiofrequency energy effects on joint capsular tissue: potential treatment for joint instability: an in vivo mechanical, morphological, and biochemical study using an ovine model. Am J Sports Med 1999;27:761-71.

11. PötzI W, Witt KA, Hackenberg L, Heusner T, Steinbeck J. Influence of postoperative immobilization on tendon length after RF-induced shrinkage: an in vivo rabbit study. Am J Sports Med 2003;31:36-40.

12. Pullin JG, Collier MA, Johnson LL, De Bault LE, Walls RC. Holmium: YAG laserassisted capsular shift in a canine model: intraarticular pressure and histologic observations. J Shoulder Elbow Surg 1997;6:272-85.

13. Schulz MM, Lee TO, Sandusky MD, Tibore JE, McMahon PJ. The healing effects on the biomechanical properties of joint capsular tissue treatment with $\mathrm{Ho}$ : YAG laser: an in vivo rabbit study. Arthroscopy 2001;17:342-7.

14. Wallace AL, Hollinshead RM, Frank CB. Creep behavior of a rabbit model of ligament laxity after electrothermal shrinkage in vivo. Am J Sports Med 2002;30:98-102.

15. Fitzgerald BT, Watson BT, Lapoint JM. The use of thermal capsulorraphy in the treatment of multidirectional instability. J Shoulder Elbow Surg 2002;11:108-13.

16. Levitz CL, Dugas J, Andrews JR. The use of arthroscopic thermal caspsulorrhaphy to treat internal impingement in baseball players. Arthroscopy 2001;17:573-7.

17. Lyons TR, Griffith PL, Savoie FH 3rd, Field LD. Laser-assisted capsulorrhaphy for multidirectional instability of the shoulder. Arthroscopy 2001;17:25-30

18. Savoie FH 3rd, Field LD. Thermal versus suture treatment of symptomatic capsular laxity. Clin Sports Med 2000;19:63-75.

19. Hayashi K, Thabit G 3rd, Vailas AC, et al. The effect of nonablative laser energy on joint capsular properties: an in vitro histologic and biochemical study using a rabbit model. Am J Sports Med 1996;24:640-6.

20. Hayashi K, Massa KL, Thabit G 3rd. Histologic evaluation of the glenohumeral joint capsule after the laser-assisted capsular shift procedure for glenohumeral instability. Am J Sports Med 1999;27:162-7.

21. Hayashi $\mathbf{K}$, Hecht $\mathbf{P}$, Thabit $\mathbf{G}$ 3rd, et al. The biologic response to laser thermal modification in an in vivo sheep model. Clin Orthop 2000;373:265-76.

22. Hecht $\mathbf{P}$, Hayashi $\mathbf{K}$, Cooley AJ, et al. The thermal effect of monopolar radiofrequency energy on the properties of joint capsule: an in vivo histologic study using a sheep model. Am J Sports Med 1998;26:808-14.

23. Lopez MJ, Hayashi K, Fanton GS, et al. The effect of radiofrequency energy on the ultrastructure of joint capsular collagen. Arthroscopy 1998;14:495-501.

24. Rodeo SA, Suzuki K, Yamauchi M, Bhargava M, Wassen BF. Analysis of collagen and elastic fibers in shoulder capsule in patients with shoulder instability. $A m ~ J$ Sports Med 1998;26:634-43. 